\title{
OBSERVATORIO
}

\section{Muchos cambios y algunas certezas para las bibliotecas de investigación, especializadas y centros de documentación}

\author{
Many changes and some certainties for research and \\ special libraries, and documentation centers
}

Lluís M. Anglada

Cómo citar este artículo:

Anglada, Lluís M. (2019). “Muchos cambios y algunas certezas para las bibliotecas de investigación, especializadas y centros de documentación". El profesional de la información, v. 28, n. 1, e280113.

https://doi.org/10.3145/epi.2019.ene.13

Artículo recibido el 05-02-2019

Aceptación definitiva: 12-02-2019

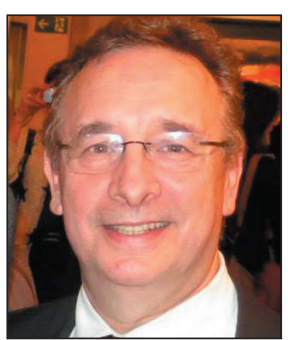

\author{
Lluís M. Anglada $\square$ \\ http://orcid.org/0000-0002-6384-4927 \\ Consorci de Serveis Universitaris de Catalunya (CSUC). \\ Àrea de Ciència Oberta \\ Gran Capità, 2-4, edif. Nexus, 4a pl. 08034 Barcelona, \\ España \\ langlada@gmail.com
}

\section{Resumen}

El artículo argumenta que a pesar de los muchos cambios que están experimentando las bibliotecas de investigación, especializadas y los centros de documentación, que les ocasionan dudas sobre su futuro, existen algunas certezas que permiten que estos centros puedan dirigir adecuadamente sus actividades. Se propone distinguir entre cambios menores y cambios profundos y se afirma que, para los centros de información, el cambio fundamental es el haber pasado de una situación en la que la información era escasa y el tiempo para buscarla abundante a otro en el que el tiempo para buscar información es escaso y la información abundante. Esto debería reconducir las actividades de los centros de información para -siguiendo a M. Buckland- dejar de centrarse en la 'información-objeto' para hacerlo en la 'información-proceso'. Se fijan como certezas donde apoyarse diferentes aspectos de dos movimientos: el de la Ciencia Abierta y el de las Humanidades Digitales. Se examinan algunos productos documentales que reflejan un cambio en las maneras de enfocar y usar la información por parte de las personas: La Colección del Museo del Prado, Transcribe Bentham, eBird y Mapa Literari Català. Para finalizar, se recomienda a los centros de documentación, bibliotecas especializados y de investigación que orienten sus servicios a digitalizar de forma enriquecida, a vehicular la participación ciudadana, y a crear y reforzar comunidades.

\section{Palabras clave}

Bibliotecas especializadas; Centros de documentación; Gestión del cambio; Evolución; Futuro; Ciencia abierta; Humanidades digitales; Nuevos enfoques; Actividades; Sociedad de la información; Participación ciudadana. 


\begin{abstract}
It is argued that despite the many changes being experienced by research and specialized libraries, and documentation centers, which cause them doubts about their future, there are some certainties that allow these centers to properly address their activities. It is proposed to distinguish between minor and profound changes and it is affirmed that, for information centers, the fundamental change has been to go from a situation in which information was scarce and the time to look for it abundant, to another in which time to look for information is scarce and information is abundant. This should help redirect the activities of the information centers -following M. Buckland- to stop focusing on the 'information-as-an-object' to concentrate on the 'information-as-a-process'. Two consolidated movements should help them to guide their future: the Open Science and the Digital Humanities. Some information products that reflect a change in the ways people approach and use information are examined: Museo del Prado's The Collection, Transcribe Bentham, eBird and Mapa Literari Català. Finally, the author recommends to documentation centers, and specialized and research libraries to guide their services to digitize their heritage collections in an enriched manner, to promote citizen participation, and to create and strengthen communities.
\end{abstract}

\title{
Keywords
}

Special libraries; Documentation centers; Change management; Evolution; Future; Open science; Digital humanities; New approaches; Activities; Information society; Citizen participation; Croudsourcing.

\section{Cambios y más cambios ${ }^{1}$}

Vivimos una época de cambios constantes y acelerados, y esto crea en nuestra subjetividad la sensación de que cualquier cambio es permanente y bueno y que, en los tiempos que corren, gestionar es adaptarse al cambio. Pero, por mucho que el cambio caracterice la época en la que nos ha tocado vivir, no todos los cambios son iguales; los cambios pueden clasificarse por sus efectos, y así tendríamos cambios aparentes, circunstanciales, pasajeros, temporales, definitivos, profundos, fundamentales... Además, uno tiene la impresión de que la adaptación al cambio está consistiendo en dejarlo pasar a la espera del siguiente, cuando lo propio sería adoptarlo por lo que esto supone de sintonizar con el momento.

La gestión efectiva no es la adaptación inmediata a cualquier cambio, sino la diferenciación entre los muchos cambios que nos sacuden para discriminar entre modas y tendencias, y para seleccionar entre estas últimas las que debemos adoptar (ver, por ejemplo, el uso del análisis estratégico para direccionar el futuro de las bibliotecas en: Wiorogórska, 2016). Así, una respuesta cortoplacista de adaptación al cambio es debatir a través de qué canal comunicaremos (ayer Second Life, después Facebook, hoy quizá mejor Twitter, pero mañana... quién sabe), pero lo fundamental es ver, por debajo del cambio novedoso (y constante) una tendencia de profundidad que nos aconseja adoptar las redes sociales como vehículo para difundir las actividades y servicios de nuestro centro y, sobre todo, para establecer vínculos con nuestros usuarios o 'clientes'.

El problema para categorizar desapasionadamente los elementos nuevos que aparecen en el escenario profesional es su abundancia. A esto se añade el hecho de que hoy cualquier cambio tecnológico va acompañado de una valoración positiva. Muchos cambios en un marco mental de valoración alta conllevan a que no sepamos o queramos distinguir entre lo que tendrá consecuencias (sólo) a corto plazo y lo que afectará (de forma lenta pero inexorable) a nuestro futuro a partir de ahora. Miremos 40 años atrás y tomemos el CD-ROM como ejemplo. Con su aparición se inició un ciclo de cambios constantes con respecto al almacenamiento de información y fue tarea profesional estudiar las mejoras que trajeron los instrumentos que terminaron sustituyéndolo, pero al final estos aspectos no han sido más que momentos menores que ejemplifican la tendencia que importa: cada vez hay más información accesible con más facilidad desde cualquier lugar y momento (y por lo tanto, cada vez es menor el valor de la biblioteca dispensadora de información). Siguiendo a Dempsey:

“...los cambios en los comportamientos en la investigación y el aprendizaje y en las expectativas son más importantes para la biblioteca académica que cualquier otro cambio en la tecnología bibliotecaria en sí mismo (Dempsey, 2012)"

Dejemos de lado pues los cambios que podríamos denominar 'tácticos', por ser sus efectos pequeños o grandes pero poco sostenidos en el tiempo, y pasemos a fijarnos en los que podríamos denominar 'profundos', por ser sus efectos continuados a lo largo de un cierto período. Hay más de los que podemos analizar en detalle: la accesibilidad de grandes cantidades de información digital, la ubicuidad en el acceso, la tendencia de la información a ser libre, o el hecho de que la facilidad en el acceso esté sustituyendo a la calidad como criterio de selección de la información...

Pero al final, las demandas generadas por nuevos artilugios, lo que nos parecen gustos cambiantes del público, sus aproximaciones variables al consumo de información, dependen en parte de los medios a través de los que se accede a la 
información, pero sobre todo de su posición en el contexto vital de las necesidades humanas. El cambio fundamental y director es que hemos pasado de un contexto en el que la información era escasa y el tiempo para buscarla abundante, a otro en el que el tiempo para buscar información es escaso y la información abundante. En un contexto de infoabundancia para los centros de información, lo importante no es tener sino enseñar, y, para el consumidor, lo determinante es menos obtener información que incorporarla a la vida cotidiana a través sus procesos habituales y el vivirla como experiencia (Anglada, 2016).

Podemos entender mejor este cambio recordando los distintos significados que tiene la palabra 'información' en el artículo seminal de Buckland (1991). Éste distingue entre la información como objeto (information-as-thing), la información como proceso (information-as-process) y la información como conocimiento (information-as-knowledge). A pesar de que la 'información' que nos interesa es el conocimiento, no hay conocimiento sin información procesada, ni proceso sin información que deglutir.

Casi toda la biblioteconomía hecha hasta ahora se ha centrado en la información objeto. Lógico, en un contexto de información escasa, lo primero es recoger, y luego

\section{En el cambio de paradigma que esta- mos viviendo, la información pasa a ser abundante y se comodiza}

-claro- organizar. El documento como objeto (cómo lo guardamos, cómo lo clasificamos, cómo lo hacemos accesible...) ha construido nuestros conocimientos profesionales y ha sido totalmente normal que la biblioteconomía moderna centrara su atención en maximizar los usos (presentes y futuros) de los documentos en la información como objeto. Cuando el primer y principal obstáculo para acceder a la información es conocer de su existencia y acceder físicamente a ella, facilitar el proceso de estar informado no es una prioridad.

Pero en el cambio de paradigma que estamos viviendo, la información pasa a ser abundante y se comodiza. La dedicación a guardar, indexar y difundir documentos pasa de las personas a las máquinas y la biblioteconomía debe dirigir su atención hacia cómo facilitar que la información se incorpore a los flujos de trabajo y procesos cotidianos de investigadores y ciudadanos. El uso de información dependerá menos de su tratamiento físico que del trabajo que puedan hacer los centros de información para adaptar sus técnicas a los procesos intelectuales tal como nos vienen modulados por la época que vivimos.

Así pues, si ha lugar redefinir la biblioteca para el futuro -cosa que ciertamente tiene sentido hacer-, no ha de ser a partir de un nuevo marco tecnológico sino a partir de un nuevo marco sociológico -e incluso me atrevería a decir antropológico-. Olvidemos los soportes documentales y preguntémonos qué necesidades cubría y qué necesidades debe cubrir la biblioteca o centro de documentación y qué 'lenguaje' debe emplear para hablar con sus usuarios. En una fase de estabilidad social, el evolucionismo tecnológico y el inmovilismo organizativo son la receta; en fases de cambios sociales profundos, debemos hacer reajustes en la manera en que hacemos las cosas para garantizar el poder seguir haciéndolas con la finalidad para la que nacimos.

Archiveros, bibliotecarios, documentalistas e incluso museólogos tenemos el objetivo profesional común de procesar información para que ésta pueda ser encontrada y utilizada con facilidad por el ciudadano y el investigador. Para ello nos hemos valido en el pasado, y lo estamos haciendo en el presente, de diferentes avances tecnológicos (muchos de ellos creados fuera de nuestro ámbito profesional) que aplicamos a nuestras actividades. En las últimas décadas los avances están siendo de tal magnitud que a veces monopolizan nuestra atención y alejan los debates profesionales del objeto mismo de la profesión.

El tecnosolucionismo (Morozov, 2015) no es una enfermedad exclusiva de los infonomistas, (término acuñado por Alfons Cornella, que quizá es el que mejor describe esta "multiprofesión", ver Cobarsí; Canals; Ortoll, 2016), pero nosotros no hemos desarrollado poderosas defensas ni tan siquiera prevenciones contra la misma. Por experiencia propia vemos como la tecnología soluciona hoy problemas que eran insolubles hace pocos años y quedamos admirados hasta la fascinación en el 'cómo se hace', dejando algo de lado el 'por qué lo queríamos hacer'. Mientras que el 'cómo lo hacemos' subdivide al sector en múltiples subdisciplinas profesionales, el 'por qué lo hacemos' afecta por igual a todas ellas. Hay tendencias que creo que afectan y afectarán a todas las organizaciones gestoras de información, aunque en estos momentos puedan parecer alejadas de las preocupaciones principales de la subespecialidad profesional en la que cada uno anda metido. La adaptación organizacional de archivos, bibliotecas y centros de documentación a las necesidades de información de la cambiante sociedad que los ha creado y mantiene debería ocupar un lugar bastante central en nuestros debates y preocupaciones.

\section{Algunas certezas}

Planteado así, los cambios en los gustos o preferencias de los usuarios de información deberíamos buscarlos en movimientos más amplios, en tendencias que están reconfigurando la forma de trabajar y los centros de interés de los investigadores y también de los ciudadanos de a pie. Detengámonos un momento a describir brevemente las motivaciones y las consecuencias de la Ciencia Abierta y de las Humanidades Digitales. Las dos tienen efectos importantes para las bibliotecas de investigación, especializadas y los centros de documentación, si es que queremos que éstos 'hablen' el lenguaje de la época. 


\subsection{Ciencia Abierta}

El término Ciencia Abierta (Anglada; Abadal, 2018) tiene una gestación larga e interesante. En marzo de 2013, la Dirección General de Communications, Networks, Content and Technology (Connect) de la Comisión Europea, publicó un documento conceptual sobre el momento actual de la ciencia. En él se exponían de forma embrionaria los conceptos que la Comisión ya no ha dejado de usar en documentos posteriores, a saber, que internet y otras tecnologías han cambiado radicalmente la forma en que se crea y difunde el nuevo conocimiento, que este cambio necesita sustentarse en un entorno científico colaborativo y abierto, y que la nueva manera de hacer ciencia permite que ésta se acerque a la sociedad.

Los motivos de la Comisión Europea para preocuparse por los cambios en la manera de hacer ciencia son político-sociales y quedan bien explicados con unas palabras de Jean-Claude Juncker, su presidente:

"La investigación y la innovación crean oportunidades de inversión para nuevos y mejores productos y servicios y, por tanto, incrementan la competitividad y el empleo" (European Commission, 2016).

Pero el movimiento de la Ciencia Abierta tiene también motivaciones científicas ya que quiere adecuar la comunicación científica a las posibilidades tecnológicas actuales y aumentar su eficacia haciendo que la ciencia sea más rápida, certera y reutilizable. Lo que el concepto de Ciencia Abierta pone de manifiesto es que, debido a los cambios tecnológicos recientes, la ciencia, sin haber modificado sus motivaciones y objetivos, sí lo ha hecho con su manera de operar. Esta nueva manera de hacer ciencia se fundamenta en tres criterios: la ciencia debe ser:

- abierta,

- colaborativa, y

- hecha con y para la sociedad.

La llamada europea a la Ciencia Abierta ha tenido un amplio efecto en diferentes ámbitos. Por ejemplo, algunos países han creado sus propios planes nacionales para fomentarla. Así lo han hecho Finlandia (2014), Eslovenia (2015), Portugal (2016), Holanda (2017), Francia (2018) y Serbia (2018) (Lasauca-Cisa, 2018). Pero ha tenido también efecto en entidades científicas como la European University Association o la Asociación Europea de Bibliotecas de Investigación (Liber). Vale la pena fijarse en el contenido del Liber open science roadmap (Liber, 2018) ya que en él no sólo se describen las siete áreas focales en las que podemos dividir la Ciencia Abierta, sino que en cada una de ellas se señalan las oportunidades y retos para las bibliotecas, a las que se les dan también recomendaciones para que se preparen para los efectos que tendrá este desarrollo.

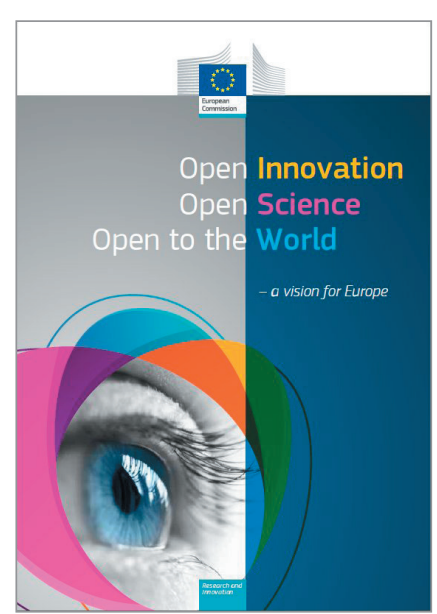

https://ec.europa.eu/digital-singlemarket/en/news/open-innovationopen-science-open-world-visioneurope

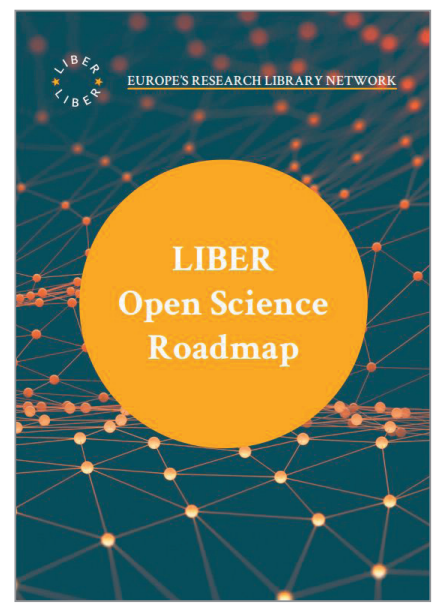

https://zenodo.org/record/1303002

\subsection{Humanidades Digitales}

El otro gran movimiento que afecta la vida y la evolución de los centros de información es el denominado Humanidades Digitales. Como cualquier conceptualización de las actividades humanas, el concepto de Humanidades Digitales es controvertido. A nuestros efectos, nos quedaremos con la definición de humanidades que da el Diccionario de la RAE²:

"conjunto de disciplinas que giran en torno al ser humano, como la literatura, la filosofía o la historia".

No hay una definición canónica de Humanidades Digitales ${ }^{3}$, pero nos valdrá decir que no es una disciplina propiamente dicha, sino una manera de trabajar, en este caso la aplicación de métodos y herramientas computacionales a problemas de investigación en humanidades ${ }^{4}$. Los métodos digitales o computacionales comparten dos características:

- a través de ordenadores tratan grandes conjuntos de datos (big data) imposibles de gestionar de forma manual, a partir de los cuales,

- construyen modelos o patrones de comportamiento, establecen correlaciones, crean simulaciones, construyen representaciones gráficas...

Las Humanidades Digitales necesitan pues objetos digitales (o digitalizados) para que éstos puedan ser tratados con instrumentos computacionales. Pero los ordenadores no pueden tratar datos si previamente no han sido documentados. Los registros catalográficos en formato MARC ${ }^{5}$ podían ser 'leídos' por un ordenador porqué los elementos bibliográficos estaban etiquetados. De forma parecida, las máquinas no pueden analizar los datos ni mostrar patrones a no ser que los datos se presenten en formatos conocidos, de forma normalizada, con la información suficiente que permita su preservación y reutilización.

Vale la pena destacar también que muchas de las actividades que en Europa consideramos de Ciencia Abierta o de Humanidades Digitales en Norte América se engloban bajo el concepto 'Digital scholarship'. Ciertamente, la afirma- 
ción anterior requiere muchas explicaciones y matices, ya que las diferencias se encuentran más en los orígenes de los conceptos respectivos que en las prácticas documentales que los mismos incluyen.

\subsection{Consecuencias para las bibliotecas}

Los movimientos de la Ciencia Abierta y de las Humanidades Digitales son un reflejo de los profundos cambios producidos en los procesos de la investigación, cambios que a su vez producen o deberían producir otros en la orientación de las bibliotecas especializadas y centros de documentación. Destaquemos los aspectos de cada movimiento con más influencia en nuestro ejercicio profesional.

Hemos visto que uno de los postulados base de la Ciencia Abierta es que la investigación debe ser hecha con y para la sociedad. Podemos parafrasear a Clemenceau y decir que la ciencia es un asunto demasiado serio como para dejarla en manos de los científicos. Si la investigación pasa a ser el motor reconocido de desarrollo económico y social, ésta debe sustentarse en los valores éticos y sociales, dirigirse a dar respuesta a los retos de la sociedad del siglo XXI e implicar a los ciudadanos.

No se trata sólo de hacer más divulgación científica. La ciencia abierta observa que, en el contexto tecnológico actual, es posible establecer una nueva relación entre las personas y la ciencia, una relación de participación. Los ciudadanos no sólo pueden interesarse más por lo que hacen los científicos, sino que pueden contribuir a la ciencia con su participación y aportaciones.

Por parte de las Humanidades Digitales los efectos son aún más claros y directos: los investigadores necesitan objetos digitales y necesitan que éstos vayan acompañados de la información sobre los procesos que los hace tratables por ordenadores, compartibles entre diferentes colectivos y reutilizables.

\section{Bibliotecas de investigación, especializadas y centros de documentación}

Después de tanto preludio, quizá sea ahora el momento de parar y examinar algunos productos documentales que reflejan este cambio en las maneras de acercarse y usar la información por parte de los individuos. Vamos a comentar brevemente cuatro iniciativas:

- La colección del Museo del Prado,

- Transcribe Bentham,

- eBird, y

- Mapa Literari Català.

\section{Museo del Prado}

La web del Museo del Prado tiene el apartado La colección en el que su director describe las colecciones del mismo y da entrada a explorar a distancia una selección de más de 16.000 obras $^{6}$. No vamos a comentar aquí la presentación y las capacidades del servicio de consulta online de las obras -que es magnífica-, pero sí algunos de sus detalles que vienen a cuento de lo tratado hasta ahora. El visitante online puede interactuar con cada obra (ampliar o reducir la imagen, fijarse en un detalle...), usarla para comunicarse a través de redes sociales (Twitter, Facebook y correo electrónico), re-

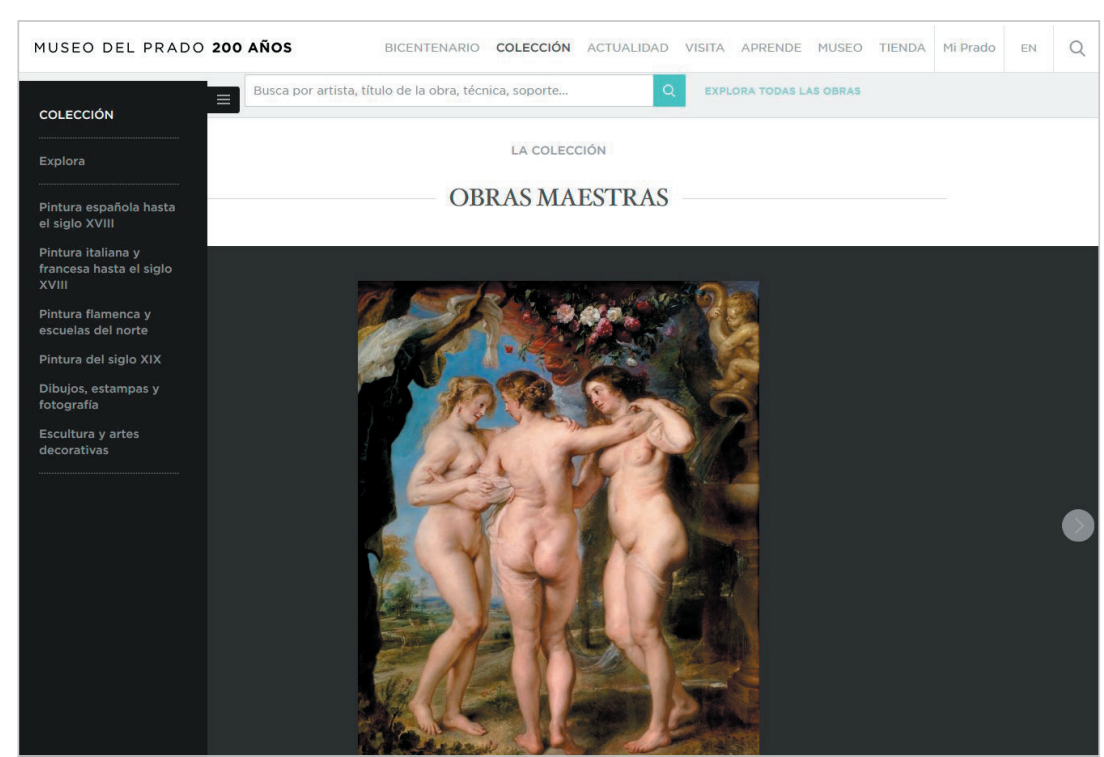

https://www.museodelprado.es/coleccion 
lacionarla con otras de la colección (a través de enlaces y etiquetas creados por los conservadores), y, finalmente, descargarla sin restricciones con lo que puede reutilizarla para lo que crea mejor (se distingue entre uso privado y comercial) ${ }^{7}$.

\section{Transcribe Bentham}

Es una iniciativa participativa basada en un proyecto de investigación de la University College London. Su objetivo es transcribir documentos manuscritos originales y no estudiados del filósofo, economista, pensador y escritor inglés Jeremy Bentham (17481832) a través de la participación ciudadana. Según el último recuento, los voluntarios han transcrito así más de 20.000 páginas de los escritos de Bentham ${ }^{8}$. El objetivo final del

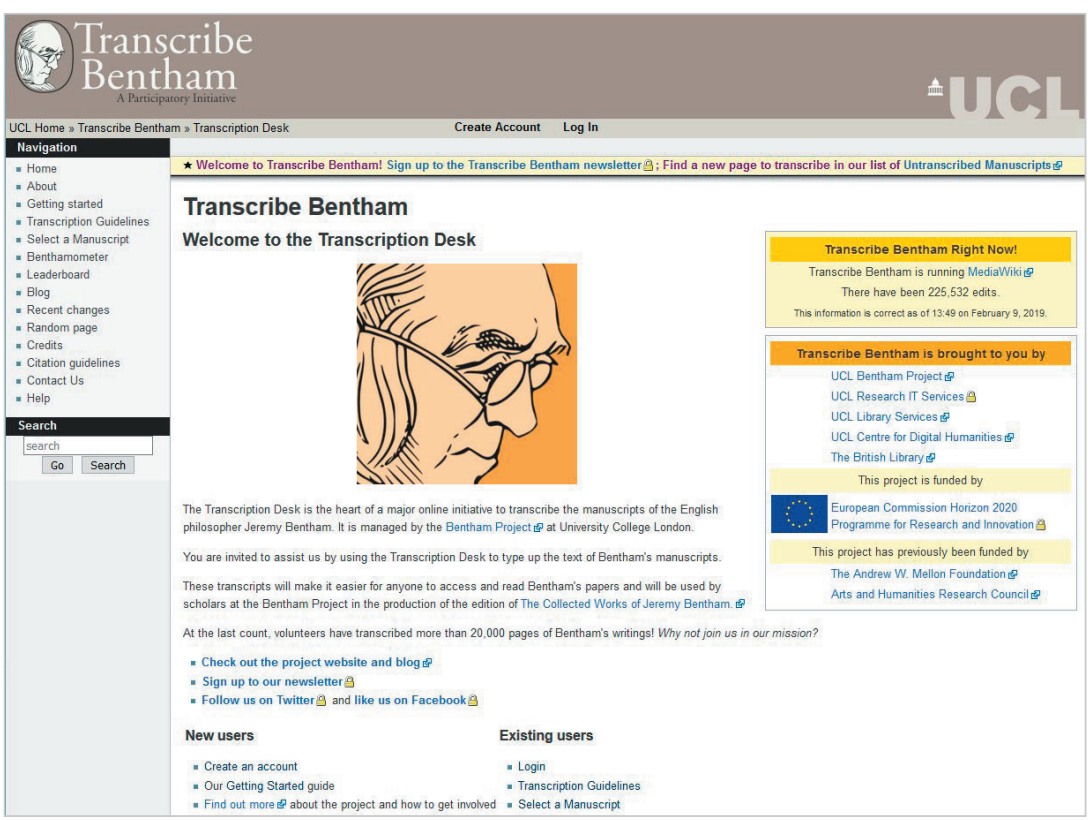

http://blogs.ucl.ac.uk/transcribe-bentham/about proyecto es científico y quiere facilitar la edición de las obras completas del filósofo, que dejó muchos manuscritos sin publicar. Pero esto lo hace a través de la participación ciudadana que se motiva de la forma siguiente:

"se contribuye así a la investigación sobre Bentham, se preserva y difunde su obra, se aprende y se desarrollan capacidades paleográficas, y... uno se lo pasa bien haciéndolo" 9 .

\section{eBird}

Este proyecto fue puesto en marcha por el Cornell Lab of Ornithology y la National Audubon Society con el objetivo de recoger información sobre las migraciones de pájaros. Esto lo consigue no con las observaciones de científicos específicamente preparados para ello, sino usando la información que proporcionan los aficionados al avistamiento de pájaros. Más de 300.000 aficionados aportan al año unos 100 millones de registros de avistamiento, una cantidad difícil de conseguir sólo con participantes profesionales. eBird no es una iniciativa diletante: la base de datos ha sido usada por científicos para estudiar la conexión entre las migraciones de aves y las lluvias monzónicas en la India, o el cambio climático, por ejemplo. Las personas que aportan información al proyecto ven que su afición contribuye a la ciencia.

\section{Mapa Literari Català (MLC)}
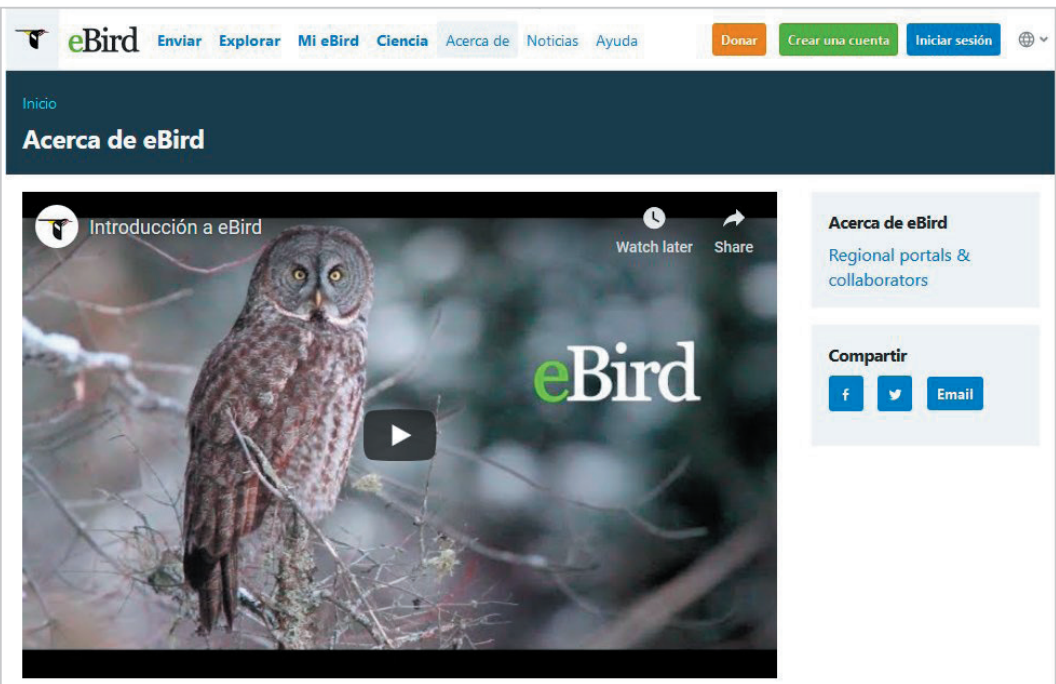

Acerca de eBird Regional portals \& collaborators Compartir $f y$ Email
- Encuentra más aves

- Ten un registro de tus listas, fotos y sonidos de aves

- Explora las últimas observaciones de alrededor del mundo

- Únete a la comunidad de pajareros más grande del mundo

- Contribuye a la ciencia y a la conservación

eBird comenzó con una idea sencilla - que cada pajarero tiene conocimientos y experiencias

únicas. Nuestra meta es recoger esta información en forma de listas de aves, archivarla, y

https://ebird.org/about

Es una aplicación web que permite consultar puntos de la geografía mundial asociados con textos de la literatura catalana. Cada localización geográfica o espacio escrito está formado por un texto relacionado con el territorio, así como toda una serie de contenidos multimedia que enriquecen la experiencia del usuario-lector (fotografías de la época de los escritores, vídeos explicativos o con el propio escritor recitando sus textos, enlaces a manuscritos y ediciones varias, traducciones...). Los escritos se completan con unas contextualizaciones para explicar los vínculos de esa obra y de su autor con el territorio. Mapa Literari Català está producido por la asociación Espais Escrits, una entidad sin afán de lucro que aglutina instituciones que conservan y promueven la lectura y estudios de los escritores patrimoniales de la literatura catalana. MLC ofrece unas cincuenta rutas literarias que permiten seguir la trayectoria vital o literaria de los escritores, fo- 
menta clubes de lectura sobre obras de autores incluidos en el mapa, mantiene una agenda de actividades literarias, ofrece citas de los autores... En resumen, fomenta experiencias alrededor de la literatura.

Desconozco el grado de participación de archiveros, bibliotecarios o documentalistas en la gestación y mantenimiento de estos productos, pero los cuatro reflejan el cambio que se ha producido recientemente en la forma en como los ciudadanos e investigadores se acercan a los documentos. La información como objeto pierde importancia mientras lo gana la información como proceso. La información en sí misma tiene valor en tanto en cuanto de ella se deriva una experiencia emocional e intelectual.

\section{Direcciones de futuro}

Estamos viviendo un momento que tiende a hacer que toda la información que una persona tendrá en cuenta esté en la Red. Esto es así por dos motivos: porqué cada vez hay más información en internet, y porqué lo que no está en ella no cuenta a efectos prácticos. A medida que ese momento llega, la biblioteca como agregador de contenidos escasos pierde valor. La manera que bibliotecas y centros de documentación tienen de ganar valor es desplazar su atención y servicios desde el documento hacia el proceso de usarlo, y cuando decimos usarlo no nos referimos sólo a facilitar su acceso sino a facilitar su reutilización y a favorecer que este uso permita y fomente la implicación, participación y empoderamiento del usuario ${ }^{10}$.

Vistos los cambios en las técnicas documentales y en el hacer diario de los usuarios de información, los documentalistas o bibliotecarios especializados, creo que tendrán el viento en la espalda -empujando- si orientan sus servicios a hacer tres cosas:

- Digitalizar de forma enriquecida

- Vehicular (fomentar) la participación ciudadana, y,

- Crear (reforzar) comunidades.

Las colecciones de las bibliotecas especializadas han sido su fortaleza, pero hemos visto que esto va a dejar de ser un valor en poco tiempo. Lo que va a continuar teniéndolo van a ser las colecciones especiales o únicas. Diversos autores (Dempsey; Malpas; Lavoie, 2014; Dempsey, 2016) consideran que el enfoque bajo el que se tratan las colecciones debe cambiar en este nuevo entorno de información digital en red. Debemos digitalizar tanto como podamos, teniendo por prioritario lo más escaso, pero ya no basta con tener imágenes de alta resolución, sino que debemos digitalizar de forma enriquecida. Reutilización es la música que suena (o la palabra clave, si lo prefieren). Reutilización por parte de los investigadores, que necesitan información detallada de los objetos digitales, reutilización por parte de los usuarios, que quién sabe lo que quieren hacer con las imágenes, y, reutilización por parte de los ordenadores que serán los que en muchos casos usaran los objetos digitales y que no pueden 'verlos', pero sí conocer sus características si estas están debidamente descritas y codificadas.

A partir de un cierto nivel de bienestar, las personas no nos conformamos con el mero disfrute de un bien, reclamamos la participación en la gestión del mismo. En muchos aspectos las bibliotecas han sido creaciones que una autoridad ilustrada ofrecía a sus administrados, pero la gente reclama (reclamamos) formar parte del movimiento. En el pasado hemos visto que la ciencia ha tendido a justificarse por si misma, pero ahora debe hacerlo mostrando que sintoniza con los valores y preocupaciones de la sociedad que la sufraga. Las bibliotecas y centros de documentación ocupan una posición de privilegio para ser quién haga de enlace entre una institución y el público al que se dirige. Este enlace puede tomar la forma de ciencia ciudadana (contribución de los ciudadanos a la ciencia aportando datos) o la de experimentación (refuerzo de los procesos de aprendizaje por co-creación), pero en cualquier caso necesita tener un agente neutral y próximo que lo facilite, y proximidad y neutralidad son características que definen a las bibliotecas (Rooney-Browne; McMenemy, 2010). 
Finalmente, nuestro enfoque profesional en los objetos portadores de información nos ha alejado del hecho que detrás de los mismos hay personas y que a estas les une un nexo que es el que justamente les conduce a visitar la biblioteca. El alto sentido social de los humanos se manifiesta en la necesidad de sentirse parte de diversos colectivos o comunidades (territoriales, de gustos o dedicaciones, de intereses...) y las bibliotecas son organizaciones con capacidad y disponibilidad de reforzar estas comunidades. Quizá nadie lo ha expresado mejor que R. David Lankes cuando redefinió la misión de las bibliotecas como la de mejorar la sociedad a través de facilitar la creación de conocimiento en sus comunidades, o cuando afirma que:

"Las bibliotecas malas construyen colecciones, las buenas bibliotecas construyen servicios, las grandes bibliotecas construyen comunidades" (Lankes, 2011; 2012).

Vivimos momentos de cambios transformadores, momentos en los que parece que adherirse a cualquier novedad tecnológica es un acierto; pero la más nueva novedad tecnológica se verá (más pronto que tarde) sustituida por una novedad más nueva. No es momento para adhesión a modas y sí para la adopción de tendencias de largo alcance. No hay otra forma de acertar en las múltiples disyuntivas con las que nos encontraremos que tener nuestra razón de ser como mecanismo discriminador. Y esta razón de ser nuestra no es coleccionar. Coleccionar es (pronto diremos, fue) el medio para la finalidad de facilitar a las personas el proceso de consumir información. Lo dice así de bien David W. Lewis a propósito de las bibliotecas universitarias:

“...tenemos que reconocer que... lo que debería tratarse no es salvar la biblioteca. Más bien... debería tratarse de ofrecer productos o servicios que puedan ayudar a los estudiantes y profesores a realizar de manera más efectiva, conveniente y económica el trabajo que han estado tratando de hacer en sus vidas académicas" (Lewis, 2016).

\section{Notas}

1. Este artículo tiene su origen en una intervención en el IX Encuentro de Centros de Documentación de Arte Contemporáneo que, bajo la coordinación de Elena Roseras Carcedo, tuvo lugar en el Museo Artium de Vitoria-Gasteiz los días 24 y 25 de octubre de 2018.

http://www.artium.org/es/explora/actividades/item/60805-ix-encuentros-de-centros-de-documentacion-de-artecontemporaneo

\section{2. https://dle.rae.es/?id=KnPZluF}

3. Quienes tengan curiosidad pueden consultar:

https://whatisdigitalhumanities.com

donde aparece una definición diferente de Humanidades Digitales cada vez que refresquen la página. Las definiciones provienen de las aportaciones a la iniciativa de "Day of $D H$ ".

4. Uso la definición que dio Núria Bel en el curso "Humanitats Digitals" (CSUC, 15-03-2018). El concepto incluiría las reflexiones críticas de los efectos de las tecnologías digitales en la cultura, pero esta acepción no tiene aplicabilidad al caso que nos ocupa.

5. El desarrollo de las siglas MARC es MAchine-Readable Cataloging.

6. El número cada vez mayor de museos que permiten consultar sus obras a distancia ha ido aumentando en los últimos años. Quizá ahora lo encontremos 'normal', pero hasta no hace mucho, los museos no daban facilidades para ver y usar reproducciones de sus obras: la digitalización de las colecciones estaba gobernada por el paradigma predigital de que poner a disposición de los usuarios copias de las obras detraería visitantes e ingresos al museo. Pero nuestra sociedad es cada vez más 'abierta' y no se concibe ya la función museística como atesoramiento patrimonial y sí como instrumento de compartición pública.

7. Con posterioridad a la conferencia dada en Vitoria veo que el Museu Nacional d'Art de Catalunya ha creado una app que permite explorar algunas de sus obras en imágenes de alta resolución. Significativamente el MNAC presenta la app así: "Disfruta de una nueva experiencia y redescubre el museo a través de un storytelling interactivo": https://www.museunacional.cat/es/articulo/una-nueva-forma-de-explorar-el-museo-la-app-second-canvas

8. Un proyecto más cercano, parecido (y a su vez diferente) al comentado es "Transcriu-me!", una iniciativa cooperativa impulsada por la Biblioteca de Catalunya con la que se han transcrito unos 4.000 documentos, entre ellos 351 pergaminos:

http://transcriu.bnc.cat

9. http://blogs.ucl.ac.uk/transcribe-bentham/about

10. Otro ejemplo, la decisión del Cleveland Museum de ofrecer en acceso abierto imágenes digitales de sus obras que 
están en el dominio público. El museo no sólo las deja 'ver', sino que "Usted las puede usar como quiera": https://www.cleveland.com/expo/life-and-culture/g66l-2019/01/fe82a74cbf1054/cleveland-museum-of-art-launchesnextgeneration-open-access-to-artworks-and-data-online-.html

\section{Referencias}

Anglada, Lluís M. (2016). "Rellenando espacios: las bibliotecas como tejido conector en una sociedad densa". En: Bibliotecas 2029: Documentos de las Jornadas. Murcia: Anabad, p. 79-83.

http://hdl.handle.net/10760/29123

Anglada, Lluís M.; Abadal, Ernest (2018). “¿Qué es la ciencia abierta?”. Anuario ThinkEPI, v. 12, pp. $292-298$. https://doi.org/10.3145/thinkepi.2018.43

Buckland, Michael K. (1991). "Information as thing”. Journal of the American Society for Information Science, v. 42, n. 5, pp. 351-360.

https://doi.org/10.1002/(SICI)1097-4571(199106)42:5<351::AID-ASI5>3.0.CO;2-3

Cobarsí-Morales, Josep; Canals, Agustí; Ortoll, Eva (2016). “Infonomista: una discusión actualizada”. El profesional de la información, v. 25, n. 2, pp. 255-261.

http://dx.doi.org/10.3145/epi.2016.mar.12

Dempsey, Lorcan (2012). "Libraries and the informational future: some notes”. En: Marchionini, Gary; Moran, Barbara B. (eds.). Information professionals 2050: Educational possibilities and pathways. Chapel Hill: School of Information and Library Science, University of North Carolina at Chapel Hill, pp. 113-126. ISBN: 9781300204862

http://sils.unc.edu/sites/default/files/publications/Information-Professionals-2050.pdf

Dempsey, Lorcan (2016). "Library collections in the life of the user: two directions”. Library quarterly, v. 24, n. 4.

Dempsey, Lorcan; Malpas, Constance; Lavoie, Brian (2014). "Collection directions: The evolution of library collections and collecting". Portal: Libraries and the academy, v. 14, n. 3, pp. 393-423.

http://www.oclc.org/research/news/2014/10-14.html

https://doi.org/10.1353/pla.2014.0013

European Commission (2016). Open innovation, open science, open to the world: A vision for Europe. Brussels: European Commission. Directorate General for Research and Innovation, p. 5.

https://ec.europa.eu/digital-single-market/en/news/open-innovation-open-science-open-world-vision-europe

Lankes, R. David (2011). The atlas of new librarianship online. MIT Presses.

https://davidlankes.org/new-librarianship/the-atlas-of-new-librarianship-online

Lankes, R. David (2012). Expect more: Demanding better libraries for today's complex world. https://davidlankes.org/wp-content/uploads/2014/01/ExpectMoreOpen.pdf

Lasauca-Cisa, Xavier (2018). "Una aproximació al concepte de ciència oberta (i 25 recursos per aprofundir-hi)". L'ase quàntic, 31 julio.

https://lasequantic.wordpress.com/2018/07/31/una-aproximacio-al-concepte-de-ciencia-oberta-i-15-recursos-peraprofundir-hi

Lewis, David W. (2016). Reimagining the academic library. Rowman \& Littlefield Publishers, p. 91. ISBN: 9781442238589

Liber (2018). Open science roadmap.

https://zenodo.org/record/1303002

Morozov, Evgeny (2015). La locura del solucionismo tecnológico. Móstoles: Katz Editores. ISBN: 9788415917199

Rooney-Browne, Christine; McMenemy, David (2010). "Public libraries as impartial spaces in a consumer society: possible, plausible, desirable?". New library world, v. 111, n. 11/12, pp. 455-467.

https://doi.org/10.1108/03074801011094831

Wiorogórska, Zuza (2016). "¿Real o imaginario? ¿Qué escenarios contemplamos para las bibliotecas? El caso de Polonia”. En: Bibliotecas 2029: Documentos de las jornadas. Murcia: Anabad, pp. 11-16.

http://hdl.handle.net/10760/29123

http://eprints.rclis.org/29123 